\title{
Stability of the spatio-temporal distribution and niche overlap in Neotropical earthworm assemblages
}

\author{
Juan-José Jiménez ${ }^{\dagger, 1}$, Thibaud Decaëns ${ }^{\ddagger}$ and Jean-Pierre Rossi ${ }^{*}$ \\ ${ }^{\dagger}$ Laboratoire d'Ecologie des Sols Tropicaux, IRD-Bondy, 32 Avenue Henri Varagnat, \\ F-93143 Bondy Cedex, France \\ * Laboratoire d'Ecologie, UFR Sciences et Techniques, Université de Rouen, \\ F-76821 Mont Saint Aignan Cedex, France \\ ${ }^{¥}$ INRA - UMR BIOGECO, Domaine de l'Hermitage Pierroton 69, route d'Arcachon, \\ F-33612 Cestas, France
}

${ }^{1}$ Corresponding author

Present address (from February 2005):

School of Environment and Natural Resources

The Ohio State University

2021 Coffey Road,

Columbus, OH 43210

USA

E-mail: Jiménez.58@ osu.edu 


\begin{abstract}
The spatial distribution of soil invertebrates is clumped with high-density patches alternating with low-density zones. Communities of these organisms are constituted by populations of different species assemblages. A high degree of spatio-temporal organization, with identified patches characterized by specific species assemblages, in which species coexist or co-occur according to assembly rules and/or competitive mechanisms for spatial and trophic resources occur. However, these studies have seldom been addressed. The spatio-temporal structure of a native earthworm community in a natural savanna and a grass-legume pasture in the Colombian "Llanos" was studied over a period of two years. A spatially explicit sampling design (regular grid) was used to unveil the distribution pattern of species assemblages in both systems by collecting earthworms from small soil cores $\left(40 \times 40 \times 15 \mathrm{~cm}^{3}\right)$ at three different sampling dates. Data collected from one metre square soil monoliths were also used in the analysis. Data were analyzed with the Partial Triadic Analysis and geostatistics (correlogram), while niche overlap was computed with the Pianka index. At the temporal scale of the sampling period earthworm communities displayed a similar stable spatial structure in both systems, characterised by an alternation of patches where different species' assemblages dominated. In both systems, a clear spatial opposition occurred in the distribution of two medium-sized endogeic species, Andiodrilus sp. and Glossodrilus sp. throughout the whole study period. The computing of the Pianka index showed a high degree of niche overlapping in several dimensions (vertical distribution, seasonality of population density) between both species. The usefulness of the PTA and Pianka index in spatial ecology studies was shown in this study. A combination of novel tools (PTA) and classical ecological indices (Pianka) allowed for some important ecological interactions in the earthworm communities to be known. The inclusion of novel tools as the PTA in soil ecology studies will certainly improve our knowledge of earthworm communities' dynamics.
\end{abstract}

Key words: Earthworm assemblages, Spatial distribution, Partial Triadic Analysis, Correlogram, Niche overlap. 


\section{Introduction}

Soil biota have long been known to be spatially aggregated but recent studies have more precisely noted the various scales of spatial patterning (Decaëns and Rossi 2001, Ettema et al. 1998, Jiménez et al. 2001, Robertson and Freckman 1995, Rossi 2003a, Rossi et al. 1997). The factors that cause and control these patterns are largely unknown and difficult to identify as spatial distribution originates from both environmental and internal population factors (Robertson and Freckman 1995, Rossi et al. 1997). The spatial distribution of soil invertebrates is also influenced, amongst other factors in a hierarchically nested scale (Lavelle 1996), by the plant cover, resulting in a horizontal mosaic of areas subjected to gradients of nutrient availability and microclimatic conditions (Lavelle 1983b). In tropical savannas this pattern is more conspicuous than in any other ecosystem since the strong and marked seasonality affects both temperature and moisture gradients. On the other hand, land use systems and agricultural practices, have been shown to directly affect soil resource patchiness (Robertson et al. 1993). Plant community composition and the distribution of soil living organisms may be affected by changes on soil heterogeneity (Tilman 1988), the type of agricultural practice determines plant community composition and soil nutrient status (Miles 1985, Wardle and Lavelle 1997).

The spatial distribution of soil organisms is complex with high-density patches alternating with low-density zones. Moreover, patches of different species may also display different temporal distributions. A replicated spatial sampling in the same area for a given period of time allows for a better comprehension of population dynamics, since it adds a significant temporal dimension to the spatial pattern of the communities of soil organisms under study. However, only recent studies on the spatial and temporal distributions of soil organisms, i.e earthworms and nematodes, have been assessed (Decaëns and Rossi 2001, Ettema et al. 1998, 2000, Ettema and Yeates 2003, Rossi 2003c). Ettema et al. (2000) analysed jointly the spatial and temporal patchiness of a nematode community to obtain a higher precision in the analysis than it was reported in a previous paper (Ettema et al. 1998).

Communities of soil invertebrates are constituted by populations of different species assemblages and show generally a high degree of spatio-temporal organization, with identified patches characterized by specific species assemblages, in which species coexist or co-occur according to assembly rules and/or competitive mechanisms for spatial and trophic resources. 
Thus, these soil invertebrates create further heterogeneity in the soil due to their activities by adding trophic and spatial "hot spots" and modifying their own and other organisms' resources (Anderson 1995, Jones et al. 1994). The spatial distribution of different taxa of soil biota has especially been addressed during the last decade (Adams 1998, Bigwood and Inouye 1988, Boag et al. 1994, Crist and Wiens 1996, Crist 1998, Delaville et al. 1996, Fromm et al. 1993, Nuutinen 1998, Poier and Richter 1992, Robertson 1994, Robertson and Freckman 1995, Rossi 2003a, b, c, Rossi et al. 1995, 1997, Stein et al. 1992, Wallace and Hawkins 1994).

The spatio-temporal distribution of earthworm communities has been analyzed using powerful and novel geostatistical tools and software that have been brought to soil biological studies (see Robertson 1987, Thioulouse and Chessel 1987, Thioulouse et al. 1997). One of the tools we have used in this study is the Partial Triadic Analysis (PTA) whose use in soil biological studies is relatively recent (Decaëns and Rossi 2001, Rossi 2003c). The PTA (Kroonenberg 1989, Thioulouse and Chessel 1987) is a multivariate method allowing to analyse a set of $\mathrm{T}$ data tables collected at $\mathrm{t}$ different sampling occasions ( $\mathrm{t} 1, \mathrm{t} 2, \mathrm{t} 3$, etc) at the same $\mathrm{s}$ location (see figure 1 in Rossi 2003c). This analysis of three-dimensional data arrays was developed by Escoufier (1973), although scarcely used in ecological studies, and afterwards it was called STATIS ("Structuration des Tableaux à Trois Indices de la Statistique") by L'Hermier des Plantes (1976). It is a Principal Component Analysis (PCA) performed on matrices with a three dimensional data array. The PTA is fully described in Thioulouse and Chessel (1987) and Kroonenberg (1989). Examples in the field of soil ecology can be found in Decaëns and Rossi (2001) and Rossi (2003c).

A statistical test aimed at determining possible autocorrelation in the common spatiotemporal pattern of earthworm assemblages was also performed (Rossi 2003c). This was achieved by using the Moran's I index (Moran 1950) for different sampling interval (see details in Sokal and Oden [1978]). The values of Moran's I index are plotted in a graph called the correlogram (Legendre and Fortin 1989, Sokal and Oden 1978), the function on which the spatial pattern of the variable analysed and the scale at which it expresses is represented (Sokal and Oden 1978). The correlogram shows the changes of autocorrelation coefficients with increasing distance classes (Sokal and Oden 1978). The interpretation of correlograms is not easy since similar correlograms might be obtained from different spatial patterns (Legendre and Fortin 1989). Contrary to semi-variogram (a structure function used in Geostatistical analysis), 
the correlogram allows testing for the presence of a significant spatial structure as well as describing its main characteristics (Legendre and Fortin 1989). Moran's I index was then calculated for the factorial coordinates of the sampling points on the first axis of the PCA in the PTA, to describe the spatial structures common to the different dates (Rossi 2003c).

To test the degree of niche overlap between species that might also be linked to opposite spatial distribution of earthworms the Pianka $\mathrm{O}_{\mathrm{jk}}$ index was used. One of the first attempts to assess and quantify the concept of coexistence (co-occurrence?) within communities was performed by Pianka (1973, 1974). In an ecological study on Mexican desert lizard communities an index based on the proportion of a given resource exploited by the entire community was computed, that was capable of measuring the degree of similarity or overlap between species. Niche overlap does not necessarily mean total competition; for example, when a given resource is abundant in the ecosystems then two competitive species shall share it without any harmful consequence for both species (Pianka 1973). Potentially competing species can also coexist in a given habitat and avoid competitive exclusion by occupying spatially and/or temporally different areas.

The present work is part of a more detailed study of earthworm communities from the Colombian savanna soils, and was especially designed to address their spatio-temporal distribution at the community level. It aimed at determining both spatial and temporal scales of variability vs. stability in species assemblages and functional groups in the natural savanna and in a grass-legume pasture over a period of two years. The hypothesis used refers to what extent the population of the earthworm community is in state of equilibrium or not throughout the 2-yr study period, and if there are changes in the spatial distribution of earthworms and their stability linked to land use management. Some of the results have been obtained from a reanalysis of previously used data set (matrices of temporal data tables). Although preliminary results already published have been included in this paper (Jiménez et al. 2001), the combination of all temporal data matrices and the use of new analytical methods, i.e. PTA, allowed us to address the temporal dimension of earthworm distribution, which was not possible in a previous paper.

\section{Materials and methods}




\subsection{Study site}

The study was carried out at the CIAT-CORPOICA Carimagua research station, in the well-drained isohyperthermic savannas of the Eastern Plains of Colombia ( $4^{\circ} 37^{\prime} \mathrm{N}$ and $71^{\circ} 19^{\prime}$ W, 175 m altitude) between September 1993 and September 1995. Climate is subhumid tropical with a four-month dry period from December to March and an average yearly rainfall and temperature of $2,280 \mathrm{~mm}$ and $26^{\circ} \mathrm{C}$, respectively (1972-1995, CIAT data). Native vegetation is characterised by open herbaceous savannas with scattered trees and bushes in the uplands ("altos") and gallery forests and palm trees ("morichales") in the low-lying savannas ("bajos"). Soils at the study site are well-drained silty clay Oxisols (Tropeptic Haplustox Isohyperthermic) in the uplands and Ultisols (Ultic Aeric Plintaquox) in the lowlands (USDA). They are characterized by their acidity $\left(\mathrm{pH}\left[\mathrm{H}_{2} \mathrm{O}\right]=4.5\right)$, a high $\mathrm{Al}$ saturation $(>80 \%)$ and low values of exchangeable $\mathrm{Ca}, \mathrm{Mg}$ and $\mathrm{K}$.

In an upland Oxisol two plots were investigated: i) a 17-yr old grazed grass-legume pasture, in a two ha plot, that combines the African grass Brachiaria decumbens Stapf. cv. Basilisk (Poaceae), and the tropical herbaceous legume Pueraria phaseoloides Benth. CIAT 9900 (Fabaceae). Cattle stocking rates were 1 animal ha $^{-1}$ in the dry season and 2 animals ha ${ }^{-1}$ in the wet season ( 1 animal unit $[\mathrm{AU}]=250 \mathrm{Kg}$ live weight). Fertilizer was applied at the following rates $\left(\mathrm{Kg} \mathrm{ha}^{-1}\right): 44 \mathrm{~K}, 14 \mathrm{Mg}$ and $22 \mathrm{~S}$ at pasture establishment and $10 \mathrm{P}, 9 \mathrm{~K}, 92.5 \mathrm{Ca}, 9 \mathrm{Mg}$ and 11.5 S each second year for the following 9 years since 1987 (Lascano and Estrada 1989) and, (ii) a native savanna as control where no management was conducted, e.g. burning or grazing, and where Andropogon bicornis L., Gymnopogon foliosus (Wild.) Nees, Panicum spp., Trachypogon spp. and Imperata brasiliensis Trin. were the most abundant plant species.

\subsection{Earthworm species}

In the natural savannas of Carimagua the earthworm community comprised 8 native species: Andiodrilus sp. (endogeic), Andiorrhinus sp.1 (endoanecic), Andiorrhinus sp.2 (endoanecic?), Aymara sp. (epigeic), Dichogaster sp. (epigeic), Glossodrilus sp. (endogeic), Martiodrilus_sp. (anecic) and Ocnerodrilidae sp. (endogeic). All these species were also present in the grasslegume pasture, where no alloctonous species were found. The main biometric characteristics, 
adaptive strategies, biology of the reproduction and life cycle of the whole earthworm community are precisely described elsewhere (Jiménez and Decaëns 2000, Jiménez et al. 1998b, 1999).

\subsection{Earthworm sampling}

Two sampling strategies were used in this study based on the data treatment:

1) Spatially explicit sampling: Earthworms were sampled from 40x40x15 cm soil cores (monoliths) taken in 64 sampling points distributed every $10 \mathrm{~m}$ in the intersections of a regular 70x70 m square grid. One soil core was sampled at each point and the soil placed on a plastic bag to manually identify and count in situ all the earthworm species and cocoons. These were later introduced together with the soil back into the monolith emplacement. Cocoons were not used in data analysis. Previous to the soil core extraction, the large tower-like fresh casts deposited by the anecic worm Martiodrilus sp. in the soil surface were counted within a $1 \mathrm{~m}^{2}$ metal frame. This allowed us to estimate the population density of the species during the rainy season in the first $10 \mathrm{~cm}$ of soil by using the direct positive relation $(\mathrm{r}=0.907, \mathrm{P}<0.01)$ between the number of individuals and the number of fresh casts present at the soil surface (Jiménez et al. 1998a,b). This was done easily as Martiodrilus sp. casts are easily distinguished from other surface depositions, either other earthworm casts or invertebrates' biogenic structures.

Each plot was surveyed following this sampling strategy at three different dates: September 1993, October 1994 and June 1995 in the grass-legume pasture, and November 1993, November 1994 and May 1995, in the native savanna. We set these sampling dates a priori since no knowledge on the biology and life cycle of the earthworm community allowed us to design the sampling campaign when some earthworms are more active in the soil. Furthermore, we later discovered that some species presented differences according to their age (Jiménez et al. 1998a, b), and because this sampling campaign was conducted within a more detailed study of the population dynamics of all earthworm species found in the area.

This sampling procedure enabled us to use spatial statistics and to sample the same area during the two years of survey. A sample size of 64 values seems rather low but it is within the range generally considered large enough to allow the use of spatial statistics (Legendre and Fortin 1989, Rossi 1996, Webster and Oliver 1992). Soil monoliths at subsequent dates (two 
more sampling dates) were taken in points separated about $50 \mathrm{~cm}$ along a spiral whose origin was represented by the point sampled at the first date. This displacement in space was however considered negligible at the scale of the plot, and sampling coordinates were taken as identical from one date to another.

2) Monthly sampling: It was designed to study in detail the population dynamics and life history of all earthworm species (not shown here). A stratified random sampling procedure was performed during 17 months (from April 1994 to September 1995, except June 1994) in both systems. In each plot 81 10x10 m square quadrates were grouped into five distinct areas. Every month earthworms were hand sorted from five $1 \times 1 \times 0.5 \mathrm{~m}^{3}$ monoliths that were taken at the center of each quadrate (randomly selected a priori) in each area and in both plots. Sampling depth varied up to $80 \mathrm{~cm}$ to follow vertical seasonal variations of some species, i.e. Martiodrilus sp. (see Jiménez and Decaëns 2000, Jiménez et al. 1998b for details). Prior to monolith extraction the number of fresh surface casts deposited by Martiodrilus sp. were counted for the same reasons as those quoted for the spatially explicit sampling. Since the efficiency of earthworm extraction varies with earthworm size and a large number of individuals are not collected, two 20x20 cm cores were sampled $1 \mathrm{~m}$ aside the $1 \mathrm{~m} 2$ monolith for washing-sieving since a correction factor to density values for those species smaller than $0.2 \mathrm{~g}$ when adults was needed (after Lavelle 1978; Jiménez et al., 2006, data not shown). Earthworms were washed in water and introduced in formaline $4 \%$. In the lab earthworms were counted to calculate population density for each species and age class. For biomass estimation complete specimens were weighed while the weight of fragmented worms (fresh weight in formaline, 15\% lower than live weight on average) was estimated by their maximum preclitellar diameter measured in fragmented worms (according to Jiménez et al. 1998b).

\subsection{The Partial Triadic Analysis as a tool to analyse multivariate spatiotemporal variability}

As mentioned in the introduction the PTA is a multivariate method allowing to analyse a set of matrices with a three dimensional data array. Consider $n$ observations (i.e. samples) on which $\mathrm{p}$ variables (the species abundance) were recorded at $\mathrm{T}$ different dates (n observations $\mathrm{X}$ $p$ variables $\mathrm{x}$ T dates). The objective of the PTA is to extract a multivariate structure that is expressed through the different dates of the reorganized data arrays. Simply expressed, the PTA 
can be seen as a three-step process. Only the first two steps were used in this work and will therefore be briefly described (Kroonenberg 1989, Thioulouse and Chessel 1987, Rossi 2003c). A first PCA is performed in order to establish the ordination of the different dates (Rossi 2003c). This analysis is called the Interstructure Analysis (IA). The IA allows a global description of sampling sites (stations) as a function of the typology of the different dates, and so extracts the common structure at different dates for any of the $\mathrm{p}$ variables. The objects of the latter analysis are the variables by samples. The scores of these objects upon the first axis of the PCA are kept for further analysis. They encapsulate certain information on the dynamics of the data tables across time.

The second step is the compromise analysis (CA) and involves a PCA of a fictitious (virtual) data table constituted by the reorganisation of the variable-sample scores. This table is referred as to the compromise table (Rossi 2003c). The CA allows a multivariate synthesis of the information expressed through the first axis of the date ordination analysis. It shows generally ecological features that are common to the dates but not necessarily since dates may exhibit some changes (e.g. seasonal dynamics). This step allows a description of sampling sites as a function of the typology of variables and the identification of the variables responsible for the common structure of the different dates.

Briefly, in this study data have been used as a chronological series of matrices of type, i.e, sampling points $\mathrm{x}$ variables (species). One matrix for each of the three years sampled. The analysis then is centered on the study of the structure of the different variables and their temporal variability, so on their stability (Thioulouse and Chessel 1987). All the computations involved in the PTA were directly processed with the module STATIS of the software ADE-4 (Thioulouse et al. 1997). Similarly graphs were drawn using the various graphical modules of the ADE-4 software.

\subsection{Moran's autocorrelogram}

A statistical test aimed at determining possible autocorrelation in the common spatiotemporal pattern of earthworm assemblages was also performed (Rossi 2003c). As mentioned above the first axis extracted from the compromise PCA is given by values that maximizes the correlation among variables, and so could be used in the same manner as if these were original 
values from the initial tables. The sample scores obtained can be used to examine the presence of spatial autocorrelation (Rossi 2003c). In this study we tested the autocorrelation in the species assemblage by analyzing only the sample score upon the first axis of the compromise analysis. The values of Moran's I index are plotted in a graph called the correlogram (Legendre and Fortin 1989, Sokal and Oden 1978), the function on which the spatial pattern of the variable analysed and the scale at which it expresses is represented (Sokal and Oden 1978). The correlogram shows the changes of autocorrelation coefficients with increasing distance classes (Sokal and Oden 1978). Data were allocated to 9 distance classes for convenience. The lower and superior limits of each class, as well as the number of pairs of points are given in the Table I. A Bonferroni corrected probability method is assessed to test for overall statistical significance of correlogram when one or several computed coefficients are statistically significant at $\alpha^{\prime}=\alpha / \mathrm{k}$, with $\alpha=5 \%$ and $\mathrm{k}$ the number of distance classes employed (Oden 1984). Each coefficient was tested at the probability level of 0.05 . The whole correlogram was considered statistically significant when at least one coefficient was significant at the Bonferroni corrected level of probability: $0.005=0.05$ / 9 (9 = number of distance classes) (Cooper 1968). When autocorrelation is positive values in that distance class are similar to those obtained in neighbouring points indicating a spatially aggregated distribution.

Moran's index was calculated using the "Autocorrélation 3.03" module of the "R Package" of Legendre and Vaudor (1991), and the normality of the frequency distribution of the data was tested with a Kolmogorov-Smirnov test before the computation of Moran's index using the "VerNorm 3.0" module of the "R Package" (Legendre and Vaudor 1991). When necessary, the Box-Cox transformation was used to reduce the asymmetry of the frequency distribution (Sokal and Rohlf 1995).

\subsection{Niche overlap (Pianka index)}

The Pianka $O_{j k}$ index ranges from 0 to 1 and the algorithm, a modification of the $\alpha$ competition coefficient (MacArthur and Levins 1967), that can be estimated for two species or groups, i.e. $j$ and $k$, is: 


$$
O_{j k}=\frac{\sum_{i}^{n} p_{i j} p_{i k}}{\sqrt{\sum_{i}^{n} p_{i j}{ }^{2} \sum_{i}^{n} p_{i k}{ }^{2}}}
$$

, where $p_{i j}$ and $p_{i k}$ are the proportion of resource $i$ used by species $j$ and $k$, respectively.

In this study, a multidimensional niche overlap was calculated from the data obtained in the monthly sampling of $1 \mathrm{~m}^{2}$ cores according to yearly average vertical stratification $(\mathrm{cm})$ of population (percentage of individuals in each soil layer) and the seasonal variations in earthworm density (monthly number of individuals $\mathrm{m}^{-2}$ from July 1994 to June 1995) in both systems sampled.

A biometric niche overlap index was also computed for the average length, weight and diameter of earthworms in addition to length/width and weight/width ratios. The size of the prostomium (where the mouth and first segment of body are) may determine to some extent the size of both organic and mineral particles earthworms ingest, so that differences in feeding regimes, of which only the diet of one species has been studied in detail (Mariani et al. 2001), might be observed. This index can then be considered as a trophic niche overlap index. Only the data collected from the $1 \mathrm{~m}^{2}$ soil monoliths were used to compute the niche overlap in the following species: Andiodrilus sp., Andiorrhinus n.sp1., Aymara sp., Glossodrilus sp., Martiodrilus sp. and Ocnerodrilidae sp. (Andiorrhinus sp2. was only found in one sample during the whole study period).

The total spatio-temporal niche overlap was calculated from each of the unidimensional niche overlap indices. This may be computed as the sum or the product of each single index, although none of them gives satisfactory results, because the sum over- and the product underestimates the actual value of the index (Pianka 1973, 1974). In this study we underestimated the $O_{j k}$ index.

\section{Results}




\subsection{Partial triadic analysis}

a) Introduced pasture

The descriptive statistics of the three temporal matrices is shown in Table II, and the interstructure analysis in figure 1. We only retained the first axis (44.9\% of total variance) of the interstructure analysis since it was clearly higher than the subsequent values. The ordination of sampling dates within the plane formed by the axes of the PCA showed an "intertable size effect" (figure 1a). This means that all sampling dates presented the same sign in relation to axis I; in other words, we observed that all correlations among data tables were positive, the spatial pattern was the same from one sampling date to another. The structure extracted in the first axis indicates that a common spatial pattern across the different dates was detected.

Mappings of the axial coordinates of the 64 sampling points upon the first axis of the IA revealed that the spatio-temporal distribution of earthworms was stable, at least during the sampling period (figure 1b). The pattern was more conspicuous for two species, i.e., Glossodrilus sp. and Andiodrilus sp. Populations of Glossodrilus sp. showed a well-delimited high-density U-shaped patch. Andiodrilus sp. had a patchy distribution within the plot with two high population density areas, one in the north-west corner and the other one at the south-east corner. These patches seemed to be in opposite areas to those occupied by Glossodrilus sp. Other patches were detected for Ocnerodrilidae sp., Martiodrilus sp. and Aymara sp., although these were small and barely distributed across the field. Ocnerodrilidae sp. was more abundant in the west zone of the field, while Martiodrilus sp. was present in the north half forming a Vshape patch and a line that crossed the plot from west to east. Andiorrhinus sp. displayed a rather scattered distribution with a more conspicuous population density patch in the east zone of the field.

In the CA the main spatio-temporal patterns of earthworm species and relationships among variables (population density) were highlighted by extracting only the first two axes, i.e $28.1 \%$ and $22.5 \%$ of total inertia, of the PCA performed on the compromise matrix. The first axis of the PCA revealed clearly an opposition between Glossodrilus sp. and Andiodrilus sp. (figure 2a). The mapping of the 64 sampling point coordinates onto the first axis showed the presence of an aggregated U-shaped zone of positive coordinate points, which corresponded to an area where 
Glossodrilus sp. (black circles) was present and where, on the contrary, the distribution of Andiodrilus sp. (white squares) was not consistent (figure $2 \mathrm{~b}$ ). A high population density patch of Andiodrilus sp. dominated the south-east area (squares, negative scores), and the north-west was occupied by Glossodrilus sp. (circles, positive values). The second axis extracted from the compromise analysis was responsible for $22.5 \%$ of total inertia, and revealed a clear spatial opposition between two species assemblages: Andiodrilus sp. / Martiodrilus sp. / Glossodrilus sp. on one hand, and Andiorrhinus n. sp1. and Ocnerodrilidae sp. on the other hand. We observed no clear spatial pattern for the second axis. Axis II showed nearly the same structure to the one displayed in the first axis (since Glossodrilus sp. also had a strong positive correlation with this axis), and the distribution pattern of Andiodrilus sp. also contributed to this axis. In fact, the definition of axis II is given by the spatial pattern of these two species. Martiodrilus sp. and Andiorrhinus n. sp1. showed opposite patterns (they both participate in the definition of Axis II but in opposite directions). Finally, Aymara sp. and Ocnerodrilidae sp. did not contribute in the definition of the axes. A detailed contour map showing the spatial distribution of Glossodrilus sp. in the introduced pasture at two sampling dates can be consulted in Jiménez et al. (2001).

b) Natural savanna

The descriptive statistics of the three temporal data matrices is shown in Table II and the IA (figure 3). The first axis of the PCA was responsible for $38.4 \%$ of total data variability, and the inter-table size effect was also detected (figure 3a). Mapping of the axial coordinates of the 64 sampling points for each species is shown in figure 3b. Population of Glossodrilus sp. was placed in a diagonal from the north-west to the south-east corner, being more abundant in the former. We also observed two high population density patches in the south area of the field for Andiodrilus sp. The epigeic Aymara sp. revealed a high population patch in the south-east corner of the field. For the rest of earthworm species we were unable to detect any spatial pattern, either because of a low population density or because of a weaker spatial autocorrelation level, except for Martiodrilus sp. in the south-west corner.

The CA showed a decrease of "eigenvalues" so we extracted the first two axes, which explained $56.0 \%$ of total data inertia $33.1 \%$ and $22.9 \%$ for the first and second axis, respectively). Briefly, the ordination of species in the plane defined by these two axes revealed 
the same general pattern that was observed in the introduced pasture, i.e. an opposite spatial pattern between population patches of Glossodrilus sp. and Andiodrilus sp. (figure 4a). Martiodrilus sp. was no longer associated with axis II because of its low and scattered population density in the native savanna (Jiménez et al. 1998a). Mappings of the 64 sampling point coordinates onto the first two axes (figure 4b) showed the spatio-temporal structure displayed by Glossodrilus sp. on the first axis (positive values, black circles) and Andiodrilus sp. (negative values, white squares). In other words, axis I showed the opposition between those areas occupied by Glossodrilus sp. compared with those areas where Andiodrilus sp. was dominant. An unclear and irregularly distributed pattern was observed for the second axis, although Aymara sp. and Ocnerodrilidae new genus sp. participated in the definition of this axis, whereas Martiodrilus sp. and Andiorrhinus sp. did not. This is the opposite result to that obtained in the grass-legume pasture. Here we observed the effect of land use system on the spatial distribution of several species that did not reach important population densities in the savanna.

\subsection{Correlograms}

In both plots studied the correlograms were statistically significant $(\mathrm{P}<0.0055)$. This means that the common spatial structure described by the PTA was also significant (figure 5a, b). Moran's autocorrelogram calculated on the factorial coordinates of the first axis showed the existence of a significant spatial structure with three significant distance classes in the grasslegume pasture (figure 5a) and only one statistically significant distance in the savanna (figure $5 b)$. Individual values of Moran's I index were significantly positive for the first and five distance classes, and negative for the third one in the pasture. Theses alternating values of the Moran's I index indicated the existence of two high-density patches of high population density of 20-30 m size, and a transition area between these two patches.

\subsection{Niche overlap}

Vertical niche separation among species was lower in the grass-legume pasture than in the natural savanna, although Pianka $O_{j k}$ index for Martiodrilus sp. was very low in the savanna, due 
to the irregular density data obtained. The index ranged from 0.51 to 0.99 (mean $=0.77$ ) in the pasture and from 0.10 to 0.98 (mean $=0.57)$ in the savanna.

The biometric niche overlap index ranged from 0.25 to 0.99 (mean $=0.69)$ and from 0.43 to $0.95($ mean $=0.75)$ in the pasture and savanna, respectively. The lowest values were obtained between large species Andiorrhinus sp. and Martiodrilus sp. and the smallest earthworm found Ocnerodrilidae sp. in both systems (biometric data of Martiodrilus sp. were not measured in the savanna due to the low quantity of individuals collected in samples).

Owing to the annual seasonal cycle of abundance the niche overlap index showed that populations of each species tended to be synchronized. In sites where a strong and rather long seasonality is present so varying soil moisture and organic matter content, as in Neotropical savannas, species are affected by the same environmental factors. The Pianka $O_{j k}$ index ranged from 0.61 to $0.88($ mean $=0.74)$ and from 0.34 to $0.89($ mean $=0.66)$ in the grass-legume pasture and the natural savanna, respectively.

The total spatio-temporal niche overlap was calculated as the product of each single $O_{j k}$ index (vertical, size and population density). There was a greater spatio-temporal niche overlap in the pasture compared with the savanna. The $O_{j k}$ index ranged from 0.13 to 0.73 (mean $\left.=0.40\right)$ in the grass-legume pasture, whereas it ranged from 0.05 to 0.56 (mean $=0.32)$ in the natural savanna, respectively.

We were able to distinguish two groups or assemblages of species: Andiodrilus / Andiorrhinus / Aymara / Glossodrilus, and Martiodrilus / Ocnerodrilidae sp. In the grass-legume pasture, Andiodrilus-Andiorrhinus (0.73), Aymara-Glossodrilus (0.65) Andiodrilus-Aymara (0.51) and Andiodrilus-Glossodrilus (0.49) showed the highest values of niche overlapping. The total niche overlap between Martiodrilus sp. and Ocnerodrilidae had a lower value (0.13) compared to the savanna, mainly due to differences in size and in the seasonal cycle of their population density. In the natural savanna the highest niche overlap within the first group was obtained for Aymara-Glossodrilus (0.56), Aymara-Ocnerodrilidae (0.54) and AndiodrilusGlossodrilus (0.52). Except for the Ocnerodrilidae earthworm, these species were usually concentrated during the rainy season in the topsoil and increased their population at the onset of the rainy season (Jiménez and Decaens 2000). Species within the second group showed a low niche overlap (0.27), although this value is probably underestimated due to the low density of Martiodrilus sp. in the savanna. 


\section{Discussion}

In this study we have demonstrated the existence of a clumped structured assemblage in the earthworm community studied in the natural savanna and the introduced grass-legume pasture, within a significant temporal stability of at least 2 -yr. The common spatial structure observed across sampling dates seems to be explained by two medium-sized endogeic species that had opposite spatio-temporal distribution patterns. Population dispersal, reproduction, mortality and competition, and the effect of land use system seem to act at very different scales. Although the population internal factors may have an influence on their spatial pattern, the environmental heterogeneity (also affected by changes in land use) also exerts an influence. Understanding the drivers of such variability is subject of further study. This would also help to develop new insights in spatial soil ecology studies (Ettema and Wardle 2002).

The range and scale of factors that determine the spatial distribution of soil organisms are not yet clearly understood. Decaëns and Rossi (2001) showed that the spatio-temporal distribution of earthworm assemblages determined some selected soil physico-chemical properties, rather than soil heterogeneity influenced the spatial distribution of earthworms. It is likely that both intra- and interspecific interactions may result in the clumped distribution commonly observed in soil organisms' population.

\subsection{Species patterns}

The observation of the spatio-temporal structure of each species taken individually from the IA reveals that distribution of individuals was characterized by an alternation of population patches of high density (20-40 m) separated from each other by areas of low density. Besides, these alternating patches correspond to presumably species with a high degree of niche overlap. Species coexistence in a community is achieved through the exhibition of partly excluded spatial and temporal distribution.

Two endogeic species like Glossodrilus sp. and Andiodrilus sp. presented a clearly clumped distribution that seemed to be highly stable across time. This pattern may be a consequence of both demographical and life history traits of these species. Whereas their high demographic rates allow them to increase rapidly their populations (Jiménez, unpubl.), their endogeic behaviour 
and their medium size imply a low displacement capacity. Hence both species are likely to display markedly aggregated distribution, which is corroborated by the Morisita's $\mathrm{I}_{\mathrm{d}}$ and Taylor b indices employed in a previous analysis (Jiménez et al. 2001).

Very small species like Aymara sp. (epigeic) and the Ocnerodrilidae sp. (endogeic) also show a visible aggregated distribution, less evident than for the previous species. Both species are commonly found close to high rich-organic hotspots, such as fecal pellets, Coleopteran nests and cattle dung (coprophagy) (Jiménez et al. 1998b, Decaëns 2000). We hypothesize that their distribution reflect local spots of trophic resources availability, although this needs to be further assessed since it has not been measured in this study. An extremely marked seasonality determines the dynamics of the tropical savannas, and earthworms develop adaptive strategies to tolerate such extreme conditions and survive during this drastic season. This is costly in terms of energetic savings for soil organisms living in poor-resource acid-soils, either in terms of energetic trade-offs or in terms of compensatory changes in the biology of these organisms. These are species with a high population growth rate ( $\mathrm{r}$ strategists), increasing their population rapidly at the onset of the rainy season. The patches of spatial pattern of these species may not last during the whole year and so be easily detected, especially when two of the sampling campaigns were conducted at the end of the rainy season. Aymara sp. showed one of the highest values of aggregation index in both systems studied (Jiménez et al. 2001).

Martiodrilus sp. (anecic) and Andiorrhinus sp1. (endoanecic), although they significantly participate to the second axis of the compromise analysis in the pasture, display weak spatiotemporal patterns. This may be interpreted as the result of a low but very effective demographic dynamics for both species. Martiodrilus sp. has been described as a K selected species regarding its adaptive strategies (Jiménez et al. 1998a), reproduction rates (Jiménez et al. 1999), and life history traits (in fact this species takes 4 years to reach maturity, Jiménez, unpubl.) and Taylor b and Morisita $I_{d}$ aggregation indices obtained for this species is the lowest obtained of the whole earthworm community (Jiménez et al. 2001). Additionally, both species are commonly observed at the soil surface after heavy rains that flood their semi-permanent U-shape vertical burrows (Jiménez and Decaëns, pers. obs.), behaviour that decreases markedly the temporal stability of population patches. In the savanna the density of both species was so low that no interpretable patterns could be provided. 
In the natural savanna, the absence of a clear spatial distribution for some earthworm species in the upper right area of the plot might be due to the presence of the grass I. brasiliensis Trin. (with more than $50 \%$ of the right side of the plot invaded only by this plant; quantitative data are not shown). This grass has large straight sharp-pointed roots that can damage seriously the earthworm body. Only the Ocnerodrilidae sp. seems not to be affected by this feature (Jiménez, pers. obs.)

\subsection{Spatial pattern of the community}

The significance of the spatial distribution of the whole earthworm community has been detected by the correlogram (Sokal and Oden 1978). Following Legendre and Fortin (1989), the type of correlogram obtained in our study suggests that the spatial structure of earthworm assemblages was more easily detected and evident in the pasture than in the savanna. The introduction of pasture has affected the size of the spatial structure but not the short-term temporal stability of the spatial distribution.

An alternation of population patches (20-40 m) where particular species assemblages dominate was clearly observed, and the overall pattern may be described at different levels of spatial organisation. These patterns have already been reported for the same earthworm community under different land use types (Decaëns and Rossi 2001) and in the African savannas of Lamto (Côte d'Ivoire) (Rossi 2003c). It must be stated, however, that this spatio-temporal structure only represents a low proportion of the total variability of the initial data matrix (50.6\% of the $44.9 \%$ explained by the first interstructure axis in the pasture, and $56 \%$ of $38.4 \%$ explained by the first interstructure axis in the savanna, respectively). This means that despite a high stability of the spatio-temporal distribution in specific earthworm assemblages, some mobility seems to occur across the plots.

In both plots, a common spatial structure observed across sampling dates seems to be explained by a spatial opposition between the two medium-sized endogeic species Glossodrilus sp. and Andiodrilus sp. A similar pattern was previously described by Decaëns and Rossi (2001) who showed the same opposite pattern between these two species across a range of different land use managements. Interestingly enough is the fact that both species present a high degree of niche overlap, which indicates a potential competition for resource between them. 
Two alternative interpretations may be proposed to explain this pattern. First, spatial opposition may be the result of a mechanism of competitive exclusion. The presence of both species in the same plot would thus be attributed to co-occurrence mechanism within a community in a non-equilibrium stage (Tilman 1982, Chesson 1985, Ives 1988, Huston and DeAngelis 1994). This hypothesis, which has been proposed by Decaëns and Rossi (2001), implies a low temporal stability of the observed spatial opposition. Second, opposition may result from competition avoidance through spatial segregation mechanism. In this case species simultaneous presence would be related to true co-existence within a community at a stage of equilibrium (Chesson 1985, Ives 1988). This would thus imply a high correlation between earthworm an environmental heterogeneity, and a resulting temporal stability of the spatial patterns. There is no evidence in our data to support one of these two hypothesis, and further investigation will be needed to clearly understand the factors responsible for the observed patterns.

The presence of different potentially competing species within a given patch (species assemblages) may also be interpreted in different ways whether the community is considered at an equilibrium or a non-equilibrium stage. Non-equilibrium hypothesis suggests that cooccurrence of species within a patch mainly result from random factors and present a high temporal instability. On the opposite, the equilibrium hypothesis suggests that within patch coexistence is a consequence of deterministic assembly rules, i.e. niche partitioning and/or small scale spatial partitioning (Atkinson and Sorrocks 1981). Both niche partitioning (Giller 1984), niche overlap reduction (Pianka 1973) and spatial partitioning, thanks to small scale environmental patchiness (Begon et al. 1996), has been proposed to explain co-existence mechanisms within soil communities (Atkinson and Sorrocks 1981). As long as heterogeneity is becoming complex, the number of species within a community increases, since the resource spectrum to be exploited by the community is wider. Those species that overlap "too much" in any niche dimension cannot coexist, and those that do coexist must differ in any resource use or niche dimension (e.g. body size or trophic morphology) that allows them to exploit different resources. In our study, species simultaneously present in a given patch had different sizes, feeding regimes and adaptive strategies (Jiménez et al. 1998b, Jiménez and Decaëns 2000, Mariani et al. 2001). In the case of Glossodrilus sp. and Andiodrilus sp., which can be temporarily present in the same patch despite their mutual spatial exclusion a reduction of their 
niche overlap through slight differences in the vertical distribution, annual density cycle and size (data not shown) may be spatially and temporarily segregate species and allow their local coexistence (Pianka 1973).

More ecological data are needed, especially a comprehensive study of the feeding regime of these species to (i) plenty quantify the degree of niche partitioning, (ii) identify which species are competing, what kind of exclusion mechanisms occur, (iii) describe the assembly rules that allow co-existence in species assemblages, and (iii) assess and quantify the availability of resources exploited by the whole earthworm community.

\subsection{Niche overlap and competition}

There are few studies on earthworm communities where the Pianka niche overlap index has been employed. Lavelle (1983b) reported average vertical niche overlap values in African savannas of Lamto (Cote d'Ivoire) to be 0.47 . Similar values were cited by Nemeth (1981) in the neotropical rainforest of Venezuela, i.e. 0.50, and Fragoso (1993) also in a tropical rainforest in the Chajul and Los Txutlas region of Mexico, obtained values for this index that ranged from 0.48 to 0.75 , respectively. The vertical niche overlap index obtained in our study was greater than in studies mentioned above. Earthworms were more abundant in the pasture topsoil than in the savanna. At Carimagua, litter quality material incorporated in the soil or root biomass (Rao 1998, Thomas et al. 1995) may be factors responsible for the species aggregation observed.

Earthworm communities from tropical sites have a greater niche overlap than those from temperate sites, due to the vertical distribution and the size of species (Fragoso and Lavelle 1992). These authors concluded that earthworm communities from temperate sites present a diet based on litter and also they are of lower size (Fragoso and Lavelle 1992, Lavelle 1983b). Lavelle $(1979,1983 b)$ reported average values of total niche overlap for the earthworm community from Lamto to be 0.35 . Several aspects are distinguished between such community and the one studied at Carimagua. In the latter system species reduced their niche overlap through changes in the yearly seasonal density cycle, although most of them were placed in the topsoil during the rainy season (Jiménez and Decaens 2000). The reduction in total niche overlap is a consequence of the reduction of one or several resources exploited by the community (Pianka 1973). Competitors may be spatially and temporarily separated or excluded. 
In this study Andiodrilus sp. and Glossodrilus sp., two endogeic species, were spatially segregated at short-temporal scale (two years). Both species reduce their niche overlap through slight differences in the vertical distribution, annual density cycle and size (data not shown). That might be the reason why both species, although spatially excluded from each other, can be temporarily present in the same area. At Lamto, however, species show a high niche overlap index and they reduce its competition through differences in the vertical distribution pattern (Lavelle 1983b).

Finally, we have demonstrated the usefulness of niche overlap concept and its measure in soil ecology. Its relation to competition (interspecific) makes studies of niche overlap relevant, and that has been our main purpose here. Niche overlap refers to the utilization of some of the same resource types (so several dimensions) by two or more species of resource consumers. Two hypotheses related to the degree of niche overlap between Andiodrilus sp. and Glossodrilus sp. can be stated here: i) population of both species are in a non-equilibrium state what indicates that there is actual competition between them and they do not co-exist but co-occur (related to the concepts of coexistence vs. co-occurrence); hence, spatial structures are only stable at a short temporal scale; ii) both species are in an equilibrium-state, and they occupy different areas with specific soil properties (texture, organic matter content, root distribution), and they co-exist due to this soil heterogeneity. The latter hypothesis means that a higher temporal stability of population is occurring and that the size of their population patches corresponds to areas of the environmental heterogeneity of the same size.

\section{Conclusions}

We considered the persistence of the spatially separated distribution patterns of two earthworm genera, Andiodrilus sp. and Glossodrilus sp. as the most striking result of this study. The findings on the inter-specific competition have also been very useful to show the degree of niche overlapping between both species. There is a "spatial partitioning" pattern between two endogeic species with a very high degree of niche overlapping. Nonetheless, we do not conclude that a competitive exclusion process is occurring. Besides, this type of information is somehow rare and still absent in soil community ecology. The spatial ecology of soil organisms must be studied together with a complete and detailed assessment of the species ecology and biology when these 
are not known, the feeding regimes, adaptive strategies and population dynamics of earthworm communities. Finally, in this study we have shown the usefulness of some novel tools in spatial ecology studies. The comparison of results obtained by the two main methods used, the PTA together with correlogram, and the Pianka index, was insightful and allowed for some important ecological interactions in the earthworm communities to be known. Furthermore, the observation that the type of land use system (savanna or pasture) changes the structure and patterns of the earthworm community is a unique and important finding for soil ecologists.

\section{Acknowledgements}

The study was supported by a grant within the Macrofauna project (EC-STD2). We wish to thank Richard Thomas, Dennis Friesen, Edgar Amézquita (CIAT), and to Jaime Triana and Darío Cárdenas (CORPOICA) for their technical and scientific assistance. The first author is deeply grateful to technicians who helped in the field during sampling campaign, Jaime Soto, José García, Guillermo Murcia and Salvador Rojas. Partial financial support was provided by the MAS (Managing Acid Soils) Consortium of the Soil, Water and Nutrient Management (SWNM) Systemwide Program. Our most sincere thanks to Patrick Lavelle (IRD), and Christien Ettema (Wageningen University) for their inputs and constructive discussions, and various anonymous referees for their useful comments on an earlier version of this paper.

\section{References}

Adams, E.S., 1998. Territory size and shape in fire ants: a model based on neighborhood interactions. Ecology 79, 1125-1134.

Anderson, J.M., 1995. Soil organisms as engineers: microsite modulation of macroscale processes. In: Jones, C.G., Lawton, J.H. (Eds.), Linking Species and Ecosystems. Chapman and Hall, London, pp 94-106.

Atkinson, W.D., Sorrocks, B., 1981. Competition on a divided and ephemeral resource: a simulation model. J. Anim. Ecol. 50, 461-471.

Begon, M., Harper, J.L., Townsend, C.R., 1996. Ecology: Individuals, Populations and Communities. $3^{\text {rd }}$ edition. Blackwell Science Ltd., Oxford. 1068 p. 
Bigwood, D.W., Inouye, D.W., 1988. Spatial pattern analysis of seed banks: an improved method and optimized sampling. Ecology 69, 497-507.

Boag, B., Legg, R.K., Neilson, R., Palmer, L.F., Hackett, C.A., 1994. The use of Taylor's power law to describe the aggregated distribution of earthworms in permanent pasture and arable soil in Scotland. Pedobiologia 38, 303-306.

Chesson, P. L., 1985. Coexistence of competitors in spatially and temporally varying environments: a look at the combined effects of different sorts of variability. Theor. Pop. Biol. 28, 263-287.

Cooper, D.W., 1968. The significance level in multiple tests made simultaneously. Heredity 23, 614-617.

Crist, T.O., Wiens, J.A., 1996. The distribution of ant colonies in a semiarid landscape: implications for community and ecosystem processes. Oikos 76, 301-311.

Crist, T.O., 1998. The spatial distribution of termites in shortgrass steppe - a geostatistical approach. Oecologia 114, 410-416.

Decaëns, T., 2000. Degradation dynamics of surface earthworm casts in grasslands of the eastern plains of Colombia. Biol. Fertil. Soils 32, 149-156.

Decaëns T., Rossi, J.-P., 2001. Spatiotemporal structure of an earthworm community and soil heterogeneity in a tropical pasture. Ecography 24, 671-682.

Delaville, L., Rossi, J.-P., Quénéhervé, P., 1996. Plant row and soil factors influencing the microspatial patterns of plant-parasitic nematodes on sugarcane in Martinique. Fund. Appl. Nematol. 19, 321-328.

Escoufier, Y., 1973. Le traitement des variables vectorielles. Biometrics 29, 750-760.

Ettema, C.H., Coleman, D.C., Vellidis, G., Lowrance, R., Rathbun, S., 1998. Spatiotemporal distribution of baterivorous nematodes and soil resources in a restores riparian wetland. Ecology 79, 2721-2734.

Ettema, C.H., Rathbun, S.L., Coleman, D.C., 2000. On spatiotemporal patchiness and the coexistence of five species of Chronogaster (Nematoda: Chronogasteridae) in a riparian wetland. Oecologia 125, 444-452.

Ettema, C.H., Wardle, D., 2002. Spatial soil ecology. Trends Ecol. Evol. 17, 177-183.

Ettema, C.H., Yeats, G.W., 2003. Nested spatial biodiversity patterns of nematode genera in a New Zealand forest and pasture soil. Soil Biol. Biochem. 35, 339-342. 
Fragoso, C., 1993. Les peuplements de vers de terre dans l'est et sud-est du Mexique. Thèse de doctorat, Université Paris VI. 228 p + annexes [in French].

Fragoso, C., Lavelle, P., 1992. Earthworm communities of tropical rain forests. Soil Biol. Biochem. 24, 1397-1408.

Fromm, H., Winer, K., Filser, J., Hantschel, R., Beese, F., 1993. The influence of soil type and cultivation system on the spatial distributions of the soil fauna and microorganisms and their interactions. Geoderma 60, 109-118.

Giller, P.S., 1984. The Community Structure and the Niche. Chapman and Hall, London.

Huston, M.A., De Angelis, D.L., 1994 Competition and coexistence: the effects of resource transport and supply rates. Am. Nat. 144, 954-977.

Ives, A. R., 1988. Covariance, coexistence and the population dynamics of two competitors using a patchy resource. J. Theor. Biol. 133, 345-361.

Jiménez, J.J., Moreno, A.G., Lavelle, P., Decaëns, T., 1998a. Population dynamics and adaptive strategies of Martiodrilus carimaguensis nov. sp. (Glossoscolecidae, Oligochaeta), a native species from the well-drained savannas of Colombia. Appl. Soil Ecol. 9, 153-160.

Jiménez, J.J., Moreno, A.G., Decaëns, T., Lavelle, P., Fisher, M.J., Thomas, R.J., 1998b. Earthworm communities in native savannas and man-made pastures of the eastern plains of Colombia. Biol. Fertil. Soils 28, 101-110.

Jiménez, J.J., Moreno, A.G., Lavelle, P., 1999. Reproductive strategies of three native earthworm species from the savannas of Carimagua (Colombia). Pedobiologia 43, 851-858.

Jiménez, J.J., Brown, G., Decaëns, T., Feijoo, A., Lavelle, P., 2000. Differences in the timing of diapause and patterns of aestivation in some tropical earthworms. Pedobiologia 44(6), 677-694.

Jiménez, J.J., Decaëns, T., 2000. Vertical distribution of earthworms in grassland soils of the Colombian Llanos. Biol. Fertil. Soils 32, 463-473.

Jiménez, J.J., Rossi, J.-P., Lavelle, P., 2001. Spatial distribution of earthworms in acid-soil savannas of the eastern plains of Colombia. Appl. Soil Ecol. 17(3), 267-278.

Jiménez, J.J., Lavelle, P., Decaëns, T., 2006. The efficiency of hand-sorting to assess the abundance and biomass of earthworm communities. Its usefulness in population dynamics and cohort analysis studies. Eur. J. Soil Biol. (in press). 
Jones, C.G., Lawton, J.H., Shachak, M., 1994. Organisms as ecosystem engineers. Oikos 69, 373-386.

Kroonenberg, P.M., 1989. The analysis of multiple tables in factorial ecology. III. Three mode principal component analysis: "analyse triadique complète”. Acta Oecol. 10(3), 245-256.

L'Hermier des Plantes, 1976. Structuration des tableaux à trois indices de la statistique. Théorie et applications d'une méthode d'analyse conjointe. Thèse de $3^{\text {ème }}$ cycle, USTL, Montpellier (in French).

Lascano, C.L., Estrada, J., 1989. Long-term productivity of legume-based and pure grass pastures in the eastern plains of Colombia. In: Proceedings of the XVI International Grassland Congress, Nice. pp. 1179-1180.

Lavelle, P., 1978. Les vers de terre de la savane de Lamto (Côte d'Ivoire): peuplements, populations et fonctions dans l'écosystème. Thèse de Doctorat, paris VI. Publ. Lab. Zool. ENS 12. 301 p. [in French]

Lavelle, P., 1979. Relations entre types écologiques et profils démographiques chez les vers de terre de la savane de Lamto (Côte d'Ivoire). Rev. Ecol. Biol. Sol. 16, 85-101.

Lavelle, P., 1983. The structure of earthworm communities. In: Satchell, J.E. (Ed.), Earthworm Ecology: from Darwin to Vermiculture. Chapman and Hall, London, pp. 449-466.

Lavelle, P., 1996. Diversity of soil fauna and ecosystem function. Biol. Int. 33, 3-16.

Legendre, P., Fourtin, M.J., 1989. Spatial pattern and ecological analysis. Vegetatio 80, 107-138.

Legendre, P., Vaudor, A., 1991. The R package: multidimensional analysis, spatial analysis. Université de Montréal, Département des Sciences Biologiques, Montréal.

Macarthur, R.H., Levins, R., 1967. The limiting similarity, convergence and divergence of coexisting species. Am. Nat. 101, 377-385.

Mariani, L., Bernier, N., Jiménez, J.J., Decaëns, T., 2001. Régime alimentaire d'un ver de terre des savanes colombiennes - une remise en question des types écologiques. C. R. Acad. Sci. Paris 324(8), 733-742.

Miles, J., 1985. Soil in the ecosystem. In: Atkinson, D., Fitter, A.H., Read, D.J., Usher, M.B. (Ed.), Ecological Interactions in Soil, Plants, Microbes and Animals. Blackwell scientific publications, Oxford, pp. 407-427

Moran, P.A.P., 1950. Notes on continuous stochastic phenomena. Biometrika 37, 17-23. 
Nemeth, A., 1981. Estudio ecológico de las lombrices de tierra (Oligochaeta) en ecosistemas de bosque húmedo tropical en San Carlos de Río Negro, territorio federal Amazonas. Tesis de grado, Universidad Central de Venezuela. 92 p. [in Spanish]

Nuutinen, V., 1998. Spatial variation of earthworm community in relation to soil properties and yield on a grass-clover field. Appl. Soil Ecol. 8, 85-94.

Oden, N.L. 1984. Assessing the significance of spatial correlograms. Geogr. Anal. 16, 1-16.

Pianka, E.R., 1973. The structure of lizard communities. Ann. Rev. Ecol. Syst. 4, 53-74.

Pianka, E.R., 1974. Niche overlap and diffuse competition. Proc. Nat. Acad. Sci. 71, 2141-2145.

Poier, K.R., Richter, J., 1992. Spatial distribution of earthworms and soil properties in an arable loess soil. Soil Biol. Biochem. 24, 1601-1608.

Rao, I.M., 1998. Root distribution and production in native and introduced pastures in the South American savannas. In: Box, J.E. (Ed.), Root Demography and their Efficiencies in Sustainable Agriculture, Grasslands and Forest Ecosystems. Kluwer Academic Publishers, Dordrecht, pp. 19-42.

Robertson, G.P., 1987. Geostatistics in ecology: interpolating with known variance. Ecology 68, 744-748.

Robertson, G.P., 1994. The impact of soil and crop management practices on soil spatial heterogeneity. In: Pankhurst, C.E., Doube, B.M., Gupta, V.V.S.R., Grace, P.R. (Ed) Soil Biota. Management in Sustainable Farming Systems. CSIRO, Melbourne, pp. 156-161.

Robertson, G.P., Freckman, D., 1995. The spatial distribution of nematode trophic groups across a cultivated ecosystem. Ecology 76, 1425-1432.

Robertson, G.P., Crum, J.R., Ellis, B.G., 1993. The spatial variability of soil resources following long-term disturbance. Oecologia 96, 451-456.

Rossi, J.-P., 1996. Statistical tool for soil biology. XI. Autocorrelogram and Mantel test. Eur. J. Soil Biol. 32, 195-203.

Rossi, J.-P., 2003a. Short-range structures in earthworm spatial distribution. Pedobiologia 47, $582-587$.

Rossi, J.-P., 2003b. Clusters in earthworm spatial distribution. Pedobiologia 47, 490-496.

Rossi, J.-P., 2003c. The spatiotemporal pattern of a tropical earthworm species assemblage and its relationship with soil structure. Pedobiologia 47, 497-503. 
Rossi, J.-P., Lavelle, P., Tondoh, J.E., 1995. Statistical tool for soil biology. X. Geostatistical analysis. Eur. J. Soil Biol. 31, 173-181.

Rossi, J.-P., Delaville, L., Quénéhervé, P., 1996. Microspatial structure of a plant-parasitic nematode community in a sugarcane field in Martinique. Appl. Soil Ecol. 3, 17-26.

Rossi, J.-P., Lavelle, .P, Albrecht, A., 1997. Relationships between spatial pattern of the endogeic earthworm Polypheretima elongata and soil heterogeneity. Soil Biol. Biochem. $29,485-488$.

Sokal, R.R., Oden, N.L., 1978. Spatial autocorrelation in biology. 1. Methodology. Biol. J. Linn. Soc. 10, 199-228.

Sokal, R.R., Rohlf, F.J., 1995. Biometry: The Principles and Practice of Statistics in Biological Research. $3^{\text {rd }}$ edition. Freeman WH and Company, New York.

Stein, A., Bekker, R.M., Blom, J.H.C., Rogaar, H., 1992. Spatial variability of earthworm populations in a permanent polder grassland. Biol. Fertil. Soils 14, 260-266.

Stork, N.E., Eggleton, P., 1992. Invertebrates as determinants and indicators of soil quality. Am. J. Alt. Agric. 7, 38-47.

Sulkava, P., Huhta, V., 1998. Habitat patchiness affects decomposition and faunal diversity: a microcosm experiment on forest floor. Oecologia 116, 390-396.

Thioulouse, J., Chessel. D., 1987. Les analyses multitableaux en écologie factorielle. I. De la thèorie d'état á la typologie de fonctionnement par l'analyse triadique. Acta Oecol. 8, 463-480.

Thioulouse, J., Chessel, D., Dolédec, S., Olivier, J.M., 1997. ADE-4: a multivariate analysis and graphical display software. Stat. Comput.7, 75-83.

Thomas, R.J., Fisher, M.J., Ayarza, M.A., Sanz, J.I., 1995. The role of forage grasses and legumes in maintaining the productivity of acid soils in Latin America. In: Lal, R., Stewart, B.A. (Ed.), Soil Management. Experimental basis for sustainability and environmental quality. Lewis publishers, Boca Raton, pp 61-83.

Tilman, D., 1982. Resource Competition and Community Structure. Monographs in Population Biology, Princeton University Press. 296 p.

Tilman, D., 1988. Plant strategies and the dynamics and structure of plant communities. Princeton University Press, Princeton. 
Wallace, M.K., Hawkins, D.M., 1994. Application of geostatistics in plant nematology. J. Nematol. 26, 626-634.

Wardle, D., Lavelle, P., 1997. Linkages between soil biota, plant litter quality and decomposition. In: Cadisch, G., Giller, K.E., (Ed.), Driven by Nature. CAB International, Wallingford. pp 107-125.

Webster, R., Oliver, M.A., 1992. Sample adequately to estimate variograms of soil properties. J. Soil Sci. 43, 177-192. 


\section{Table I}

Lower and upper limits and number of pair points for each of the 9 distance classes employed for computing the correlograms. Distance class is $11 \mathrm{~m}$.

\begin{tabular}{llll}
\hline $\begin{array}{l}\text { Distance } \\
\text { classes }\end{array}$ & $\begin{array}{l}\text { Number of pair } \\
\text { points }\end{array}$ & $\begin{array}{l}\text { Inferior } \\
\text { limit }(\mathrm{m})\end{array}$ & $\begin{array}{l}\text { Upper } \\
\text { limit }(\mathrm{m})\end{array}$ \\
\hline 1 & 112 & 0 & 11 \\
2 & 194 & 11 & 22 \\
3 & 460 & 22 & 33 \\
4 & 346 & 33 & 44 \\
5 & 380 & 44 & 55 \\
6 & 276 & 55 & 66 \\
7 & 178 & 66 & 77 \\
8 & 60 & 77 & 88 \\
9 & 10 & 88 & 99 \\
\hline
\end{tabular}


Table II

Descriptive statistics (number of individuals $\mathrm{m}^{-2} \pm$ standard deviation) obtained for each earthworm species in the savanna and pasture (data from the explicit spatial sampling).

\begin{tabular}{lllllll}
\hline Species & \multicolumn{5}{c}{ Savanna } & \multicolumn{5}{l}{ Pasture } \\
\cline { 2 - 7 } & November & November & May & September & October & June \\
& 1993 & 1994 & 1995 & 1993 & 1994 & 1995 \\
\hline Andiodrilus sp. & $2.0 \pm 4.4$ & $2.8 \pm 5.2$ & $2.5 \pm 4.4$ & $3.5 \pm 6.1$ & $4.4 \pm 8.7$ & $6.2 \pm 13.0$ \\
Andiorrhinus sp. & 0 & 0 & $0.1 \pm 0.8$ & $1.4 \pm 3.5$ & $0.2 \pm 1.1$ & $0.4 \pm 1.5$ \\
Aymara sp. & 0 & $1.4 \pm 3.6$ & $7.8 \pm 9.5$ & 0 & $0.5 \pm 1.6$ & $13.5 \pm 17.3$ \\
Glossodrilus sp. & $46.3 \pm 39.7$ & $19.0 \pm 19.7$ & $30.5 \pm 25.9$ & $66.6 \pm 55.5$ & $36.9 \pm 23.5$ & $102.5 \pm 68.4$ \\
Martiodrilus sp & 0 & $0.1 \pm 0.8$ & $0.7 \pm 2.6$ & $1.0 \pm 2.5$ & $1.9 \pm 4.6$ & $14.5 \pm 14.9$ \\
Ocnerodrilidae sp. & $2.0 \pm 6.6$ & $3.1 \pm 3.2$ & $7.0 \pm 11.8$ & 0 & $6.6 \pm 10.6$ & $18.8 \pm 23.5$ \\
\hline
\end{tabular}




\section{Legends to figures}

Fig. 1. Results from the interstructure analysis; (a) ordination of sampling dates on the factorial plan defined by the first two axes of the PCA on the interstructure matrix (b) maps of the factorial coordinates of the 64 sampling points on the first axis of the interstructure analysis for each of the six species in the pasture. Glo: Glossodrilus sp., Aym: Aymara sp., And: Andiodrilus sp., Mar: Martiodrilus sp.; Ocn: Ocnerodrilidae sp.; Anr: Andiorrhinus sp1. (circles and squares represent positive and negative scores and the surface is proportional to the corresponding value).

Fig. 2. Results of the compromise analysis from the pasture; (a) correlation circle showing the ordination of variables (species) on the factorial plan defined by the first two axes of the PCA on the compromise matrix. Inside the squares some data regarding the life history traits of species have been included: weight, demography strategy; adaptive strategy and yearly average vertical distribution in the soil (data from Jiménez and Decaëns 2000; Jiménez et al. 1998a, b, 2000), (b) maps of the factorial coordinates of the 64 sampling points on the first two axes of the PCA on the compromise matrix (circles and squares represent positive and negative scores respectively and the surface is proportional to the corresponding value).

Fig. 3. Results from the interstructure analysis; (a) ordination of sampling dates on the factorial plan defined by the first two axes of the PCA on the interstructure matrix (b) maps of the factorial coordinates of the 64 sampling points on the first axis of the interstructure analysis for each of the six species in the natural savanna. Glo: Glossodrilus sp., Aym: Aymara sp., And: Andiodrilus sp., Mar: Martiodrilus sp.; Ocn: Ocnerodrilidae sp.; Anr: Andiorrhinus sp1. (circles and squares represent positive and negative scores respectively and the surface is proportional to the corresponding value).

Fig. 4. Results of the compromise analysis from the savanna; (a) correlation circle showing the ordination of variables (species) on the factorial plan defined by the first two axes of the compromise matrix, (b) maps of the factorial coordinates of the 64 sampling points on the 
first two axes of the PCA on the compromise matrix (circles and squares represent positive and negative scores respectively and the surface is proportional to the corresponding value).

Fig. 5. Moran's I index and correlograms computed from the factorial coordinates of the 64 sampling points on axis 1 of the PCA on the compromise-matrix in the pasture (a) and in the savanna (b) $(\mathrm{O}=$ not significant; $\bullet$ = significant $)$. 


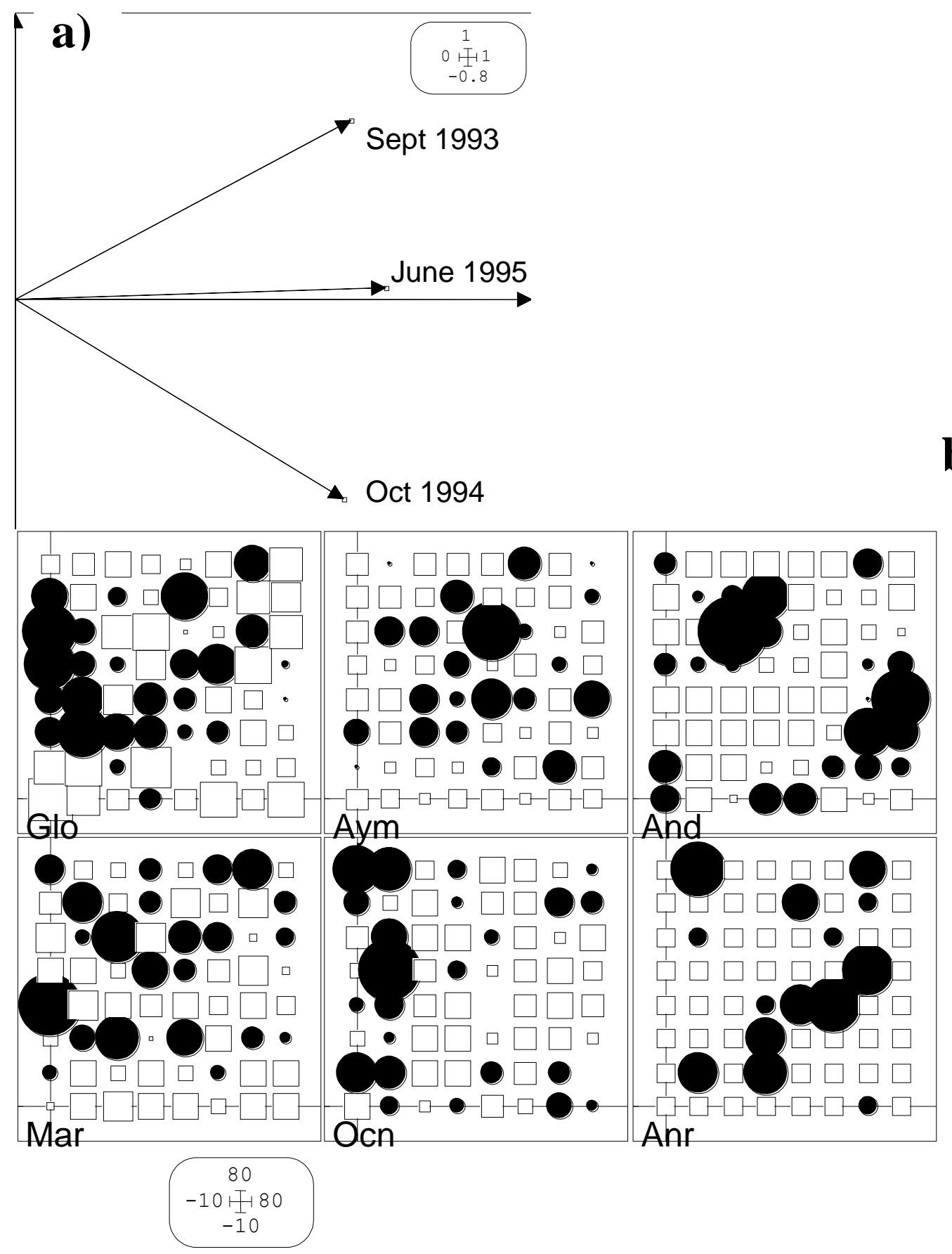

Figure 1 

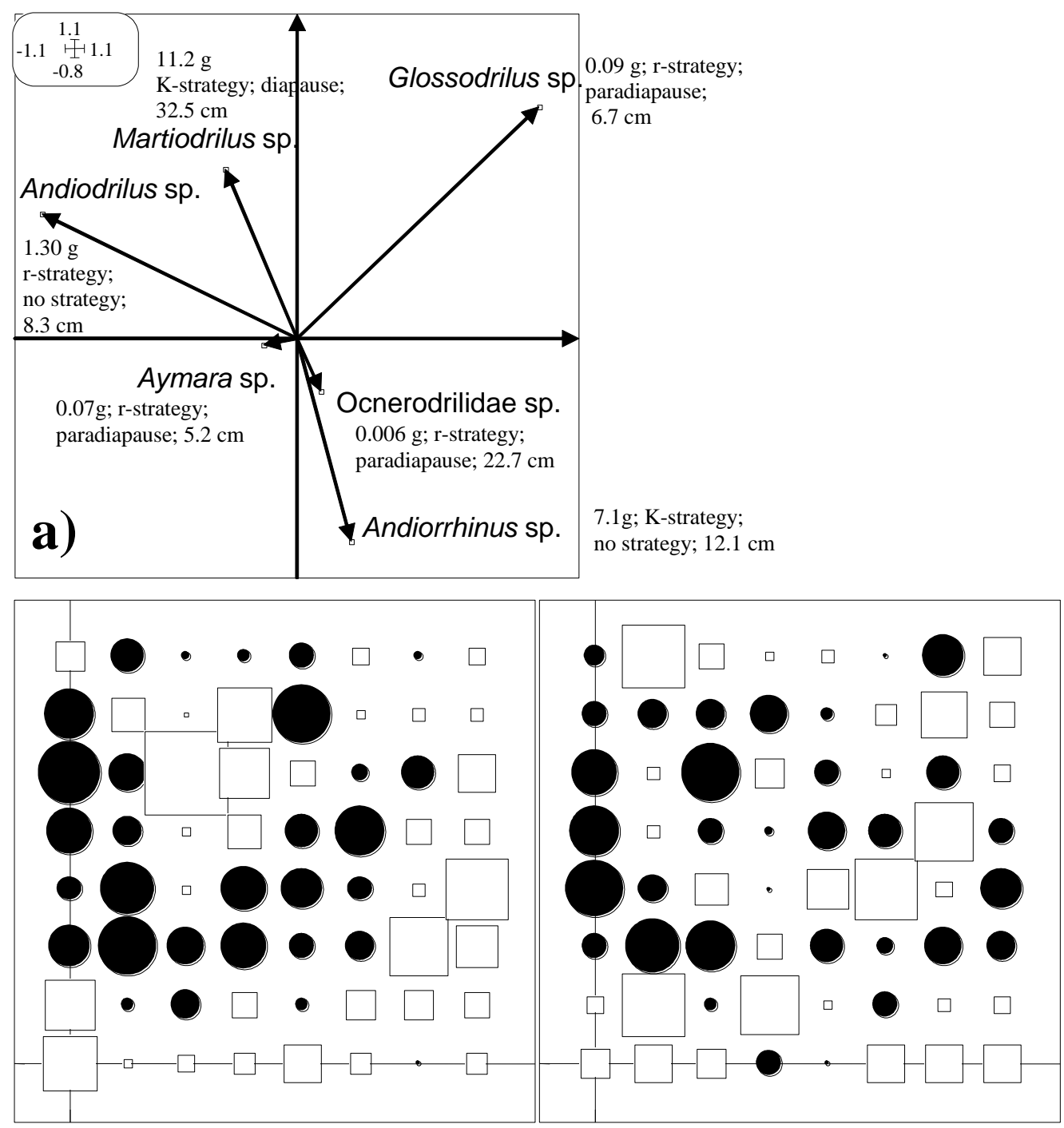

b)

$-10 \underset{-10}{80} 80$

Figure 2 


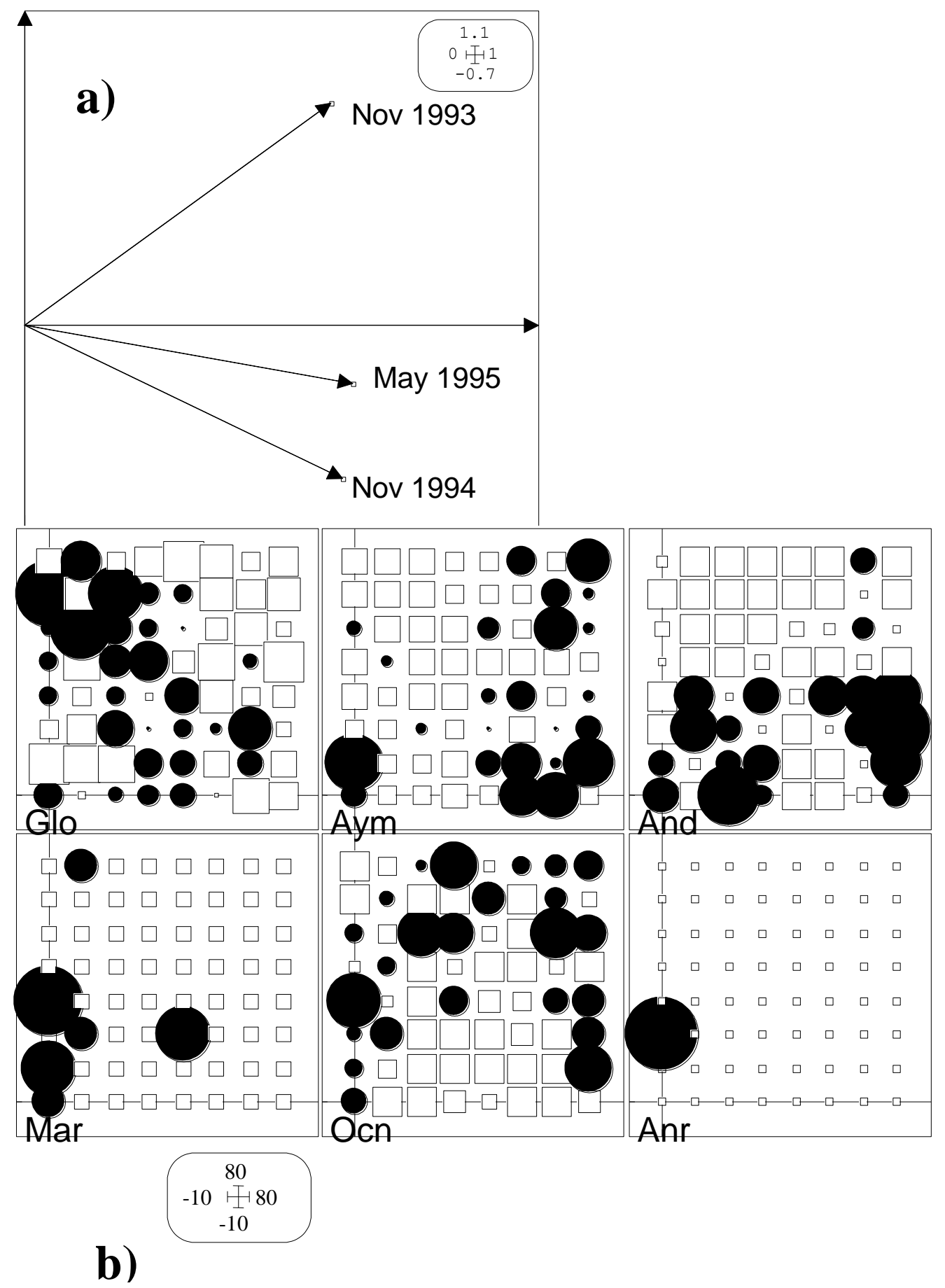

Figure 3. 


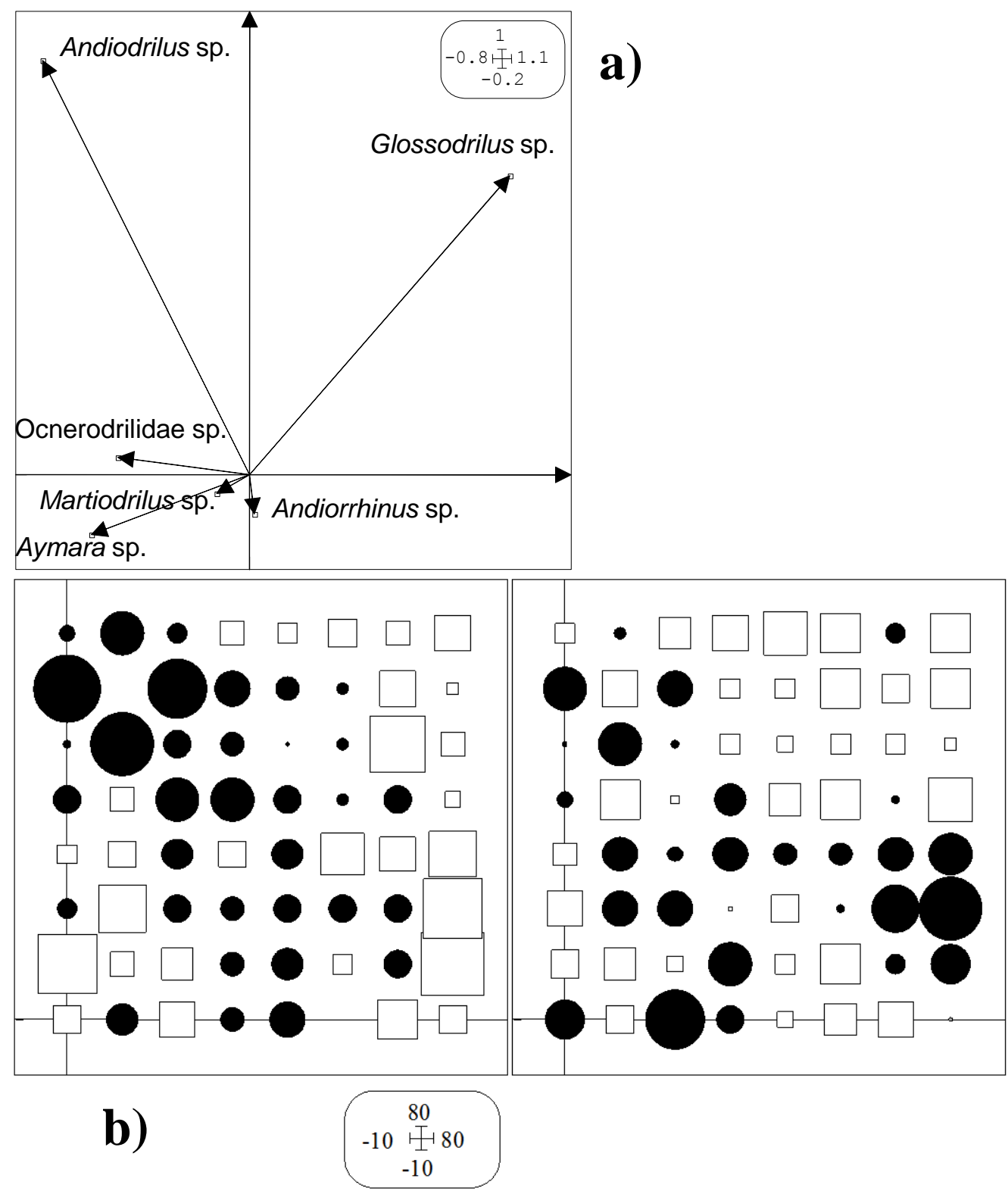

Figure 4. 


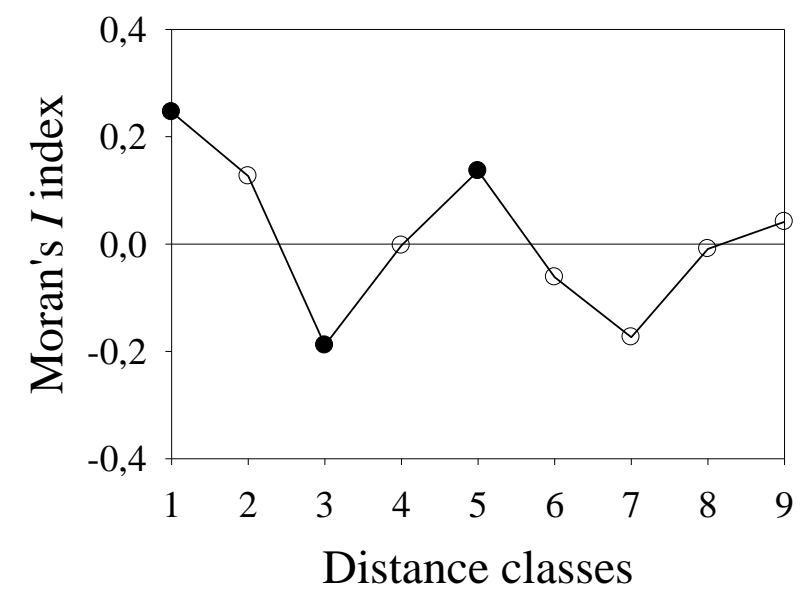

a)

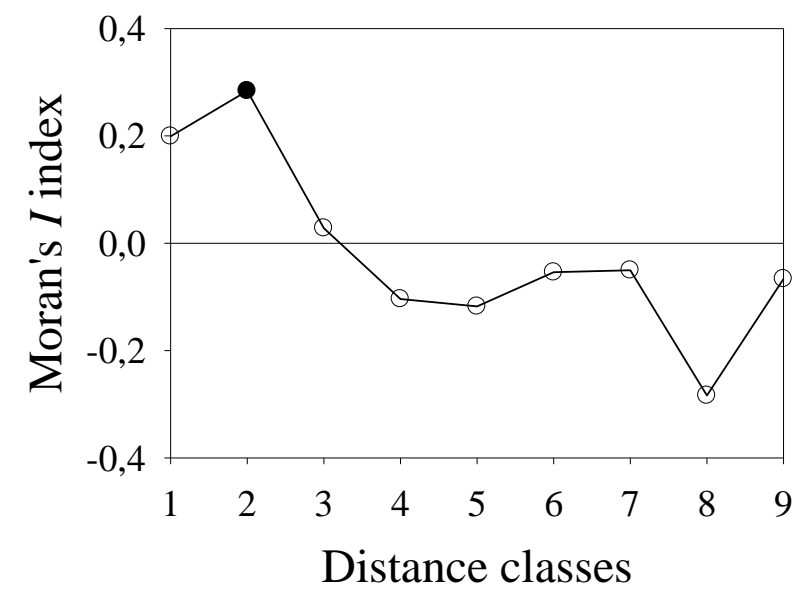

b)

Figure 5 